\title{
Pancreatoduodenectomy with Simultaneous Venous Resection for Advanced Ductal Pancreatic Head Cancer: A Case Control Study
}

\author{
Philipp R. Scherber*, Jurgita Mikneviciute, Gereon Gäbelein, Dorian Igna, Matthias Glanemann \\ Department of General-, Visceral-, Vascular- and Paediatric Surgery, Saarland University Medical Center, Homburg, Germany \\ Email: *philipp-robert.scherber@uks.eu
}

How to cite this paper: Scherber, P.R., Mikneviciute, J., Gäbelein, G., Igna, D. and Glanemann, M. (2018) Pancreatoduodenectomy with Simultaneous Venous Resection for Advanced Ductal Pancreatic Head Cancer: A Case Control Study. Surgical Science, 9, 381-398.

https://doi.org/10.4236/ss.2018.911045

Received: October 9, 2018

Accepted: November 9, 2018

Published: November 12, 2018

Copyright $\odot 2018$ by authors and Scientific Research Publishing Inc. This work is licensed under the Creative Commons Attribution International License (CC BY 4.0).

http://creativecommons.org/licenses/by/4.0/

\section{(c) $\underset{\mathrm{EY}}{\mathrm{i}}$ Open Access}

\begin{abstract}
Introduction: Surgical resection is the treatment of choice for pancreatic ductal adenocarcinoma (PDA). However, in case of venous tumor involvement, carcinomas are classified as borderline resectable and their preferential therapy remains controversial. The purpose of this study is to analyze the effectiveness of the surgical approach with simultaneous venous resection regarding perioperative outcome and long-term survival. Patients and methods: All patients that underwent pancreatoduodenectomy (PD) for PDA at our institution between 02/2002 and 12/2016 were analyzed retrospectively. A matched-pair analysis between patients that underwent PD with simultaneous venous resection (PDVR) and standard PD was performed to compare perioperative parameters, survival and factors relevant to long-term survival. Results: The study included 142 patients: 71 underwent PDVR and 71 underwent standard PD. Venous tumor infiltration could histopathologically be confirmed in 21 patients (29.58\%). PDVR wasn't associated with a higher rate of postoperative complications (56.34\% for both groups), severe postoperative complications $(28.17 \%$ vs. $23.94 \%)$ and mortality (5.63\% vs. $9.86 \%)$ compared to standard PD. Median overall survival of both groups was 17 months (95\% CI 10.89 - 23.11), without statistical significance between the two groups (PD 22 months, 95\% CI 16.02 - 27.99 vs. PDVR 16 months, 95\% CI $9.96-22.04, p=0.087)$. Parameters associated with overall survival were histopathologically proven venous tumor infiltration, the lymph node status and the necessity of postoperative blood transfusions. Conclusion: PDVR is justified, because peri- and post-operative morbidity and mortality, as well as long-term survival, are comparable to standard PD. Even in case of postoperatively histopathologically confirmed venous tumor infiltration, patients benefit over palliative treatment.
\end{abstract}




\section{Keywords}

Pancreas, Pancreatic Cancer, Extended Pancreatoduodenectomy, Pancreatoduodenectomy with Venous Resection, Borderline Resectable Pancreatic Cancer

\section{Introduction}

Pancreatic ductal adenocarcinoma is the most common type of pancreatic cancer [1]. The mortality rate is roughly the same than its incidence [2]. Hence, pancreatic ductal adenocarcinoma is one of the most aggressive malignancies in the gastrointestinal system and the fourth leading cause of cancer related death [3] [4]. Surgery, especially the resection with microscopical negative margins (R0), is the treatment of choice and the strongest predictor for long-term survival [5] [6] [7] [8].

Unfortunately, less than a quarter of all patients with pancreatic head cancer are suitable candidates for primary resection [9], since the majority of patients suffer from locally advanced or metastatic disease at the time of diagnosis [10].

Among the latter, there is a subgroup of patients with venous tumor involvement (superior mesenteric vein [SMV] or/and portal vein [PV]) on preoperative imaging. For these patients, the standard treatment is still in the discussion: besides surgical resection followed by chemotherapy, which is the standard care for primary resectable tumors and performed increasingly in high volume centers, palliative therapy and neoadjuvant chemotherapy are alternative therapeutic options [11]. There are various arguments in favor or against the therapeutic strategies mentioned previously. First, the differentiation between a vascular tumor infiltration on the one hand or a venous involvement by a peritumoral inflammation process on the other hand is hardly possible based on preoperative imaging [12] [13]. Second, it is still in debate if venous tumor infiltration is only a result of tumor location and tumor extension [12] [14] [15] or whether it is an indication for a particularly aggressive tumor biology [16] [17] [18] [19]. Furthermore, a preoperative chemotherapy might reduce tumor extent and improve the R0 resectability and survival in case of tumor response [14] [20] [21], but if the tumor expands during the neoadjuvant therapy, patients lose their prospect of cure.

At the present day as well as in the near future, there is no and not likely will be a prospective randomized evaluation of venous resection within the whipple or the pylorus preserving whipple procedure, because it is hardly possible to discriminate between a direct tumor infiltration into the vein or only an inflammatory tumor adherence to the vessel, both on preoperative imaging and on intraoperative exploration. Furthermore, inter-surgeon variation in the interpretation of the adherence has to be taken into account with regard to the reliability of the results [22]. In addition, patients' consent to a trial that might waive tumor re- 
section even if technically feasible will be limited, beside the fact that the study itself is ethically questionable.

The intention of this study is to compare the long-term survival of patients who underwent pancreatoduodenectomy (PD) with simultaneous venous resection (SMV or/and PV) to the one of patients with standard PD and moreover to examine if there is a difference between patients with infiltrative or only inflammatory venous tumor adherence. Additionally, we want to identify the strongest predictors for long-term survival after PD with venous resection. Furthermore, we intend to analyze the morbidity and mortality between the standard and the extended procedure.

\section{Patients and Methods}

Clinicopathological characteristics of the patients were derived from our pancreaticobiliary database at the Department of General- and Visceral-Surgery, Saarland University Medical Center, Homburg/Germany.

All patients that underwent PD in curative intend due to pancreatic head cancer between February 2002 and December 2016 were analyzed retrospectively. Patients with metastatic disease and any tumor other than ductal adenocarcinoma of the pancreatic head were excluded from the study. Furthermore, patients with incomplete data acquisition were excluded, too. Before surgery, all patients included in the study have given their written consent to collect and analyze their data anonymously.

Standard PD comprised the en bloc removal of the pancreatic head, the common bile duct, the gallbladder, the duodenum and the lymphadenectomy of the levels 1 and 2. The pylorus and the distal part of the stomach were only resected if there was a direct involvement by the tumor. The reconstruction was performed either by a pancreatogastrostomy or a side to side pancreaticojejunostomy, an end to side hepaticojejunostomy and a retrocolic or orthotopic end to side anastomosis between the post-pyloric duodenum or the stomach and the jejunum.

In case of tumor adherence or infiltration into the PV and/or SMV, a pancreatoduodenectomy with simultaneous venous resection (PDVR) was performed which means that the relevant segment of the vein had to be resected, too. Depending on the extent of tumor involvement, a wedge resection or the resection of the entire segment of the vein with primary anastomosis or interposition of a graft had to be performed.

Peri- and postoperative variables being analyzed were patient characteristics of age, gender and ASA Score; operation time, blood loss, number of intraoperative as well as postoperative transfused blood units; and postoperative complications such as pancreatic fistula (as defined by the International Study Group of Pancreatic Surgery (ISGPS) [23], delayed gastric emptying, bleeding, non- pancreatic anastomotic leak (bile leak or gastrojejunostomy leak) and the need for relaparotomy within the same hospital stay. 
Preoperative information about tumor extension related to the SMV or/and PV was standardized taken from the preoperative CT scan.

In hospital mortality was defined as death before discharge from hospital. Data about patients overall survival were taken from patients' relatives, general practitioners, oncologists or from the cancer registry.

Pathological analysis included the size of the tumor itself (T1, tumor limited to the pancreas, $\leq 2 \mathrm{~cm}$ in greatest dimension; T2, tumor limited to the pancreas, $>2 \mathrm{~cm}$ in greatest dimension; T3, tumor extends beyond the pancreas, but without involvement of the celiac axis or the superior mesenteric artery; T4, tumor involves the celiac axis or the superior mesenteric artery), the lymph node status (N0, no regional lymph node metastases; N1, regional lymph node metastases), the number of harvested and the number of positive lymph nodes, as well as lymphvascular and perineural infiltration, and the invasion of the SMV and/or PV in case of simultaneous resection. Furthermore, the residual tumor classification (R0, no residual tumor; R1, microscopic residual tumor; R2, macroscopic residual tumor) and the tumor grading (G1, well differentiated; G2, moderately differentiated; G3, poorly differentiated) were analyzed. This tumor grading classification is consistent to the seventh edition of the American Joint Committee on Cancer staging system [24].

In order to assess the impact of extended PD with simultaneous venous resection on morbidity and mortality, we built a matched-pair analysis, based on the type of surgery that was performed, between patients that underwent PDVR (group 1) and those who underwent standard PD (group 2) in consideration of age, gender and ASA Score.

Data were reported as mean or median values, standard deviations and frequencies. Student T-Test was used for continuous variables if they were distributed normally and Mann-Whitney-U Test if not. Chi-square test was applied in order to compare categorical variables. For all tests, two sided $\mathrm{p}$ value of $\leq 0.05$ was considered statistically significant. Kaplan-Meier method was used in order to estimate long-term survival and the log rank test in order to analyze the difference between the two groups. Variables that showed a strong correlation with long-term survival in the univariate analysis ( $p$-value $<0.20)$ were afterwards tested in multivariate model. SPSS software, version 23 was used for statistical analysis (SPSS Inc, Chicago, Ill).

\section{Results}

\subsection{Demographic Data}

Within the 15 years study period from February 2002 to December 2016 a total of 76 patients underwent pancreatoduodenectomy with en-bloc resection of the SMV or/and PV for pancreatic head adenocarcinoma with tumor adherence or infiltration into the large veins (Figure 1) at the authors' institution. Five out of the 76 patients had to be excluded from the study due to incomplete data acquisition and follow-up. The median age of the remaining 71 patients, 38 men and 


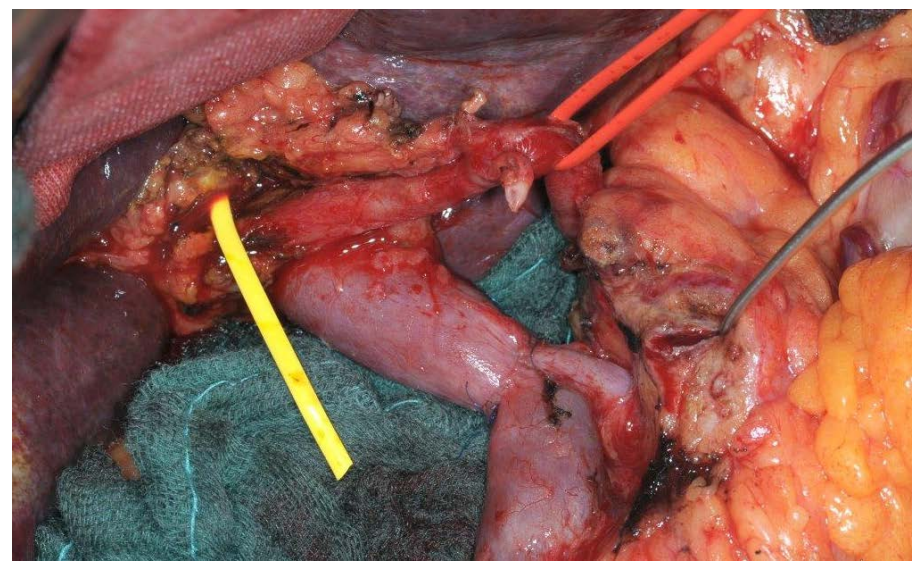

Figure 1. Intraoperative situs after pancreatoduodenectomy with portal vein resection and end-to-end reconstruction.

33 women, (group 1) at the time of surgery was 68.48 years (range 49 - 84 years). Most of them were classified as ASA (American Society of Anesthesiologists) 2 (45 Patients, 63\%); none of the patients as ASA 1 or 4.

For each of these 71 patients we found a matched patient that underwent standard PD after exclusion of a venous tumor involvement at the same period (group 2). There were no statistically significant differences between the two groups in terms of gender, age and ASA-Score (Table 1).

None of the patients, neither in group 1 nor in group 2, had received a neoadjuvant therapy.

\subsection{Tumor Characteristics}

On final histopathological examination the majority of tumors were classified as pT3: 64 tumors (90.14\%) in group 1 and $56(78.87 \%)$ in group 2, p $=0.773$. In 21 of the 71 specimens with simultaneous venous resection due to macroscopic suspected venous tumor involvement the infiltration could histopathologically be confirmed (29.58\% venous tumor infiltration).

The number of patients with positive lymph nodes ( $\mathrm{pN} 1$ status) was higher in group $1(\mathrm{n}=52,73.24 \%)$ than in group $2(\mathrm{n}=44,61.97 \%)$, but without statistic significance $(\mathrm{p}=0.154)$. In the subgroup of patients with histopathologically proven venous tumor infiltration, all but four patients (80.95\%) had a $\mathrm{pN} 1$ status. Both the number of harvested lymph nodes and the number of positive lymph nodes per patient were significantly higher in the PDVR group than in the PD group (20.47 \pm 9.99 vs. $16.42 \pm 8.41$ harvested lymph nodes, $\mathrm{p}=0.025$; and $3.35 \pm 4.13$ vs. $1.73 \pm 1.94$ positive lymph nodes, $\mathrm{p}=0.011$ ). Among the patients with PDVR there was no statistically significant difference regarding the number of harvested or positive lymph nodes between those with histopathologically proven venous tumor infiltration and those without.

Furthermore, statistical analysis revealed no significant differences between the two groups regarding the lymph vascular, perineural invasion or tumor grading. 
Table 1. Demographic data of the 142 patients that underwent PD for pancreatic ductal adenocarcinoma stratified by the underlying operation.

\begin{tabular}{cccc}
\hline & Group 1 (PDVR) n $=71$ & Group 2 (PD) $\mathrm{n}=71$ & p-value \\
\hline Age, years (range) & $68.50(49-84)$ & $68.00(24-83)$ & 0.975 \\
Gender & & & \\
male (\%) & $38(53.52)$ & $38(53.52)$ & 1 \\
female (\%) & $33(46.48)$ & $33(46.48)$ & \\
ASA-Score & & & 1 \\
$2(\%)$ & $45(63.38)$ & $45(63.38)$ & \\
$3(\%)$ & $26(36.62)$ & $26(36.62)$ & \\
\hline
\end{tabular}

ASA-Score $=$ American Society of Anesthesiologists-Score.

The rate of R0 resections was significantly higher in group 2 than in group 1 ( $71.83 \%$ vs. $53.52 \%, p=0.024)$. Patients with histopathologically proven venous tumor infiltration had a higher incidence of R1 resections $(61.90 \%$ vs. $38.10 \%, p$ $=0.156)$.

\subsection{Surgical Therapy and Peri-, Post-Operative Outcome}

Between group 1 and 2 statistical analysis revealed no significant differences with respect to median operative time (PDVR 249 min [range 117 - $473 \mathrm{~min}$ ], PD 252 min [range 122 - $515 \mathrm{~min}$ ]) and median estimated blood loss (PDVR $400 \mathrm{ml}$ [range $100-3000 \mathrm{ml}$ ], PD $400 \mathrm{ml}$ [range $50-2000 \mathrm{ml}$ ]). Nevertheless, the number of patients that had received perioperative (17 [24.60\%] vs. 6 [8.50\%], p = 0.010 ) and postoperative blood transfusions (28 patients [39.40\%] vs. 17 patients [23.90\%], $\mathrm{p}=0.047$ ) was significantly higher in the PDVR group. During the operation, patients with PDVR received $0.87 \pm 2.46$ blood units and those who underwent PD $0.23 \pm 0.85$ blood units on average, $p=0.013$. The number of blood units that were transfused in the postoperative course did not differ significantly between the two groups.

The extent of the operation, PDVR vs. PD, did neither influence significantly the median length of stay on the intensive care unit (2 days [range 1 - 30 days] vs. 1 day [0 - 34 days]) nor the length of hospital stay (19 days [range 8 - 93 days] vs. 17 days [ 8 - 87 days]).

In the postoperative course the overall complication rate was $56.34 \%$, being equal for both groups. The incidence of major complications Clavien-Dindo $\geq 3$ (PDVR $28.17 \%$ vs. PD $23.94 \%$ ) as well as the rate of surgery associated complications (PDVR $42.25 \%$ vs. PD $45.07 \%$ ) did not differ significantly between the two groups. Altogether 11 patients (7.75\%) died within the hospital stay, 4 patients after PDVR (5.63\%) and 7 patients after PD (9.86\%), p = 0.346. Furthermore, there were no statistically significant differences between the PVDR and the PD group with regard to relevant postoperative pancreatic fistula, type B and $\mathrm{C}$ according to the definition of the ISGPF [23] (25.35\% vs. $18.31 \%)$, incidence of a postoperative bleeding ( $4.23 \%$ vs. $5.63 \%)$, delayed gastric emptying $(8.45 \%$ vs. $18.31 \%)$ or bile fistula ( $4.23 \%$ for each group) and the rate of reoperations 
(15.49\% vs. $11.27 \%)$ (Table 2 ).

\subsection{Survival Analysis}

The median overall survival of both groups was 17 months (95\% CI 10.89 23.11). Patients that underwent PD tend to have a longer overall survival compared to those after PDVR (22 months, 95\% CI 16.02 - 27.99 vs. 16 months, 95\% CI 9.96 - 22.04), but without statistical significance (Figure 2). Statistical analysis revealed a significant difference of the overall survival between patients with histopathologically proven venous tumor infiltration (12 months, 95\% CI 10.97 13.34) and not (19 months, 95 CI 13.67 - 24.33; p =0.048), whereas the overall survival of patients after PDVR without venous tumor infiltration (19 months, 95\% CI 12.45 - 25.55) and the standard PD group (22 months, 95\% CI 16.02 27.99) was almost similar, as shown in Figure 3 and Figure 4.

Other parameters with statistically significant influence on overall survival were a positive lymph nodes status on histopathological examination and the need for postoperative blood transfusions (Table 3).

Table 2. Surgical therapy and peri-, postoperative outcome of the 142 patients that underwent PD for pancreatic ductal adenocarcinoma stratified by the underlying operation.

\begin{tabular}{|c|c|c|c|c|}
\hline Variable & $\begin{array}{l}\text { Overall (PDVR } \\
+\mathrm{PD}) \mathrm{n}=142\end{array}$ & $\begin{array}{c}\text { Group } 1 \\
(\text { PDVR) } n=71\end{array}$ & $\begin{array}{c}\text { Group } 2(\mathrm{PD}) \\
\mathrm{n}=71\end{array}$ & $\mathrm{p}$-value \\
\hline Median operative time, $\min$ (range) & $250(117-515)$ & $249(117-473)$ & $252(122-515)$ & 0.264 \\
\hline Median estimated blood loss, ml (range) & $400(50-3000)$ & $400(100-3000)$ & $400(50-2000)$ & 0.293 \\
\hline $\begin{array}{l}\text { Any postoperative complications, } \\
\text { patients }(\%)\end{array}$ & $80(56.34)$ & $40(56.34)$ & $40(56.34)$ & 1 \\
\hline $\begin{array}{l}\text { Major postoperative complications, } \\
\text { patients (\%) }\end{array}$ & $37(26.06)$ & $20(28.17)$ & $17(23.94)$ & 0.566 \\
\hline $\begin{array}{l}\text { Surgery associated postoperative } \\
\text { complications, patients (\%) }\end{array}$ & $62(43.66)$ & $30(42.25)$ & $32(45.07)$ & 0.735 \\
\hline $\begin{array}{l}\text { Perioperative blood transfusion, patients } \\
(\%)\end{array}$ & $23(16.40)$ & $17(24.60)$ & $6(8.50)$ & 0.010 \\
\hline Blood units perioperative per patient & $0.49 \pm 1.72$ & $0.87 \pm 2.46$ & $0.23 \pm 0.85$ & 0.013 \\
\hline $\begin{array}{l}\text { Postoperative blood transfusion, patients } \\
(\%)\end{array}$ & $45(31.70)$ & $28(39.40)$ & $17(23.90)$ & 0.047 \\
\hline Blood units postoperative per patient & $1.42 \pm 3.39$ & $1.49 \pm 3.02$ & $1.35 \pm 3.75$ & 0.092 \\
\hline $\begin{array}{l}\text { Relevant POPF, ISGPF Grade B and C, } \\
\text { patients (\%) }\end{array}$ & $31(21.83)$ & $18(25.35)$ & $13(18.31)$ & 0.415 \\
\hline Postoperative bleeding, patients (\%) & $7(4.93)$ & $3(4.23)$ & $4(5.63)$ & 0.698 \\
\hline DGE, patients (\%) & $19(13.38)$ & $6(8.45)$ & $13(18.31)$ & 0.084 \\
\hline Bile fistula, patients (\%) & $6(4.23)$ & $3(4.23)$ & $3(4.23)$ & 1.000 \\
\hline Reoperation, patients (\%) & $19(13.38)$ & $11(15.49)$ & $8(11.27)$ & 0.460 \\
\hline Median ICU-stay, days (range) & $2(0-34)$ & $2(1-30)$ & $1(0-34)$ & 0.114 \\
\hline Median hospital-stay, days (range) & $18(8-93)$ & $19(8-93)$ & $17(8-87)$ & 0.504 \\
\hline Intrahospital mortility, patients (\%) & $11(7.75)$ & $4(5.63)$ & $7(9.86)$ & 0.346 \\
\hline
\end{tabular}

$\mathrm{PD}=$ Pancreatoduodenectomy; PDVR = Pancreatoduodenectomy with simultaneous venous resection; POPF $=$ Postoperative pancreatic fistula; ISGPF = International Study Group of Pancreatic Fistula; DGE = Delayed gastric emptying; ICU = Intensive care unit. 


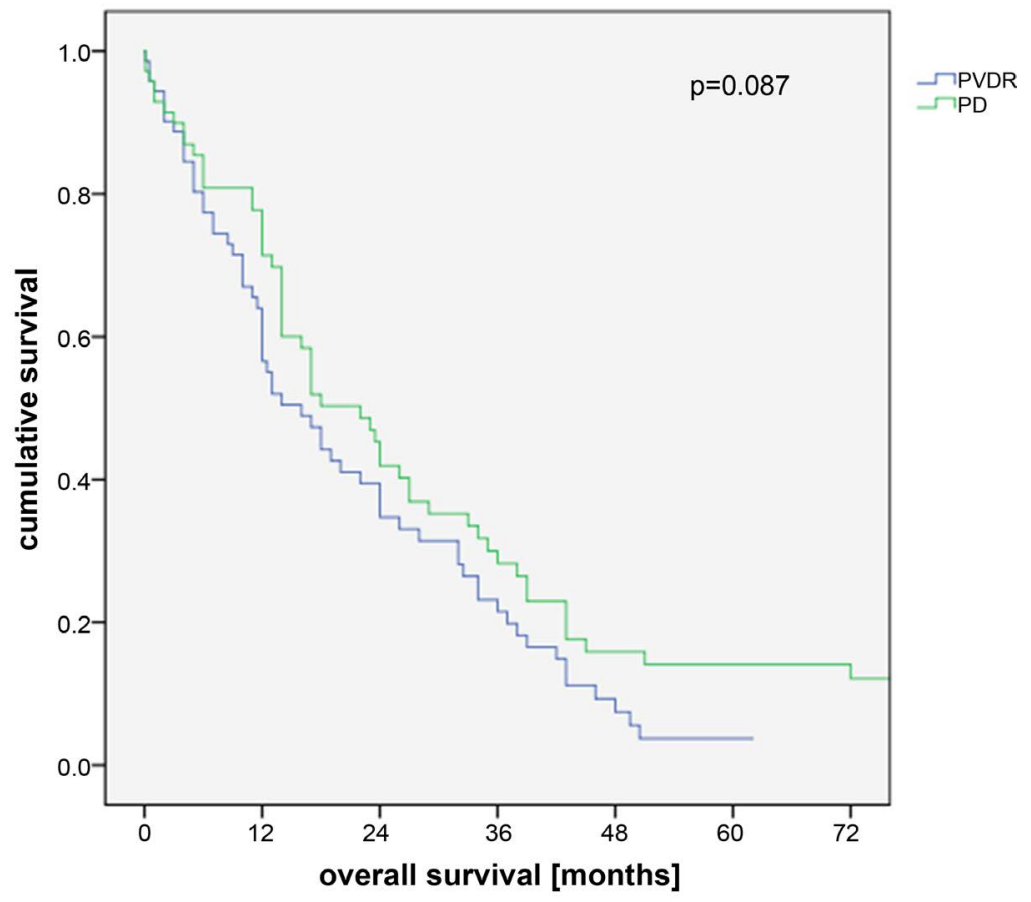

Figure 2. Overall survival after resection of pancreatic ductal adenocarcinoma stratified by the type of surgery. PD = Pancreatoduodenectomy; PDVR = Pancreatoduodenectomy with simultaneous venous resection (22 months, $95 \%$ CI $16.02-27.99$ vs. 16 months, $95 \%$ CI 9.96 - 22.04).

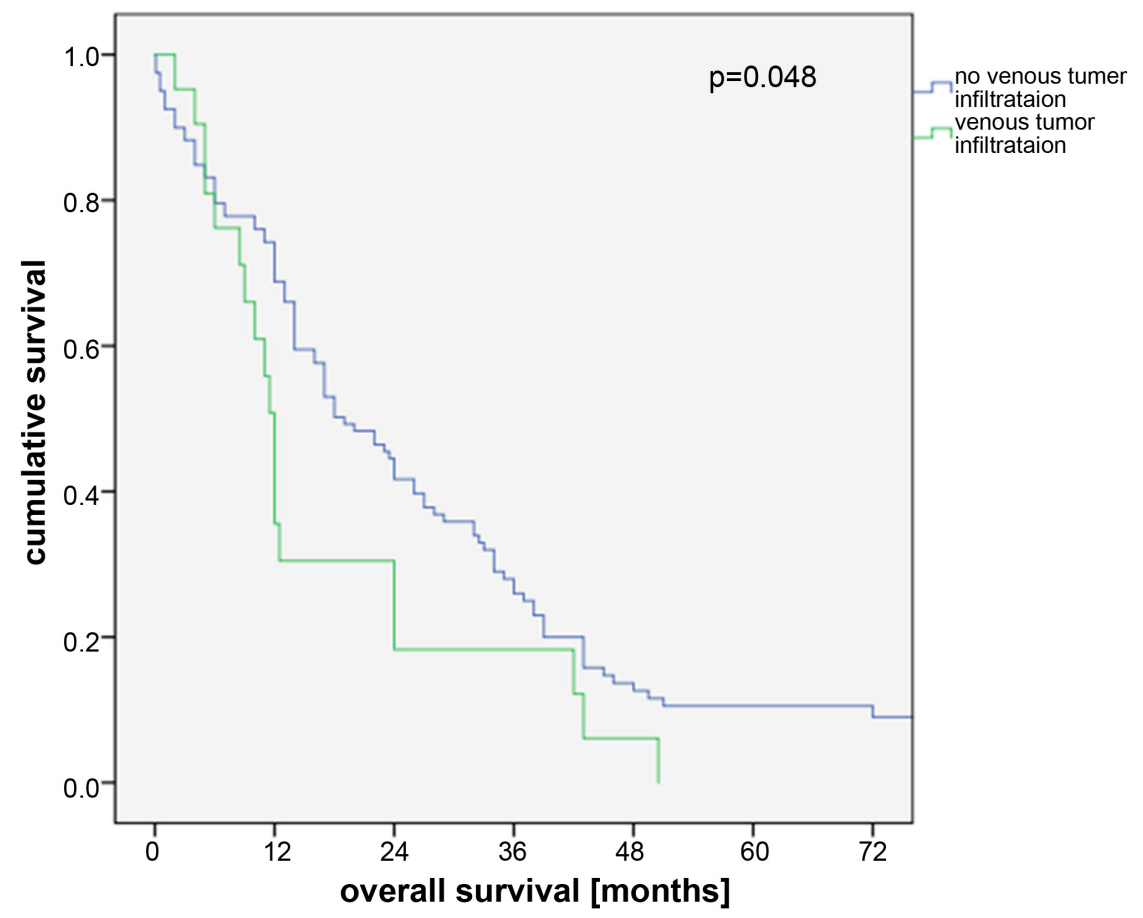

Figure 3. Overall survival after resection of pancreatic ductal adenocarcinoma stratified by proven venous tumor infiltration. PD = Pancreatoduodenectomy; PDVR = Pancreatoduodenectomy with simultaneous venous resection (19 months, 95 CI 13.67 - 24.33 vs. 12 months, 95\% CI 10.97 - 13.34). 


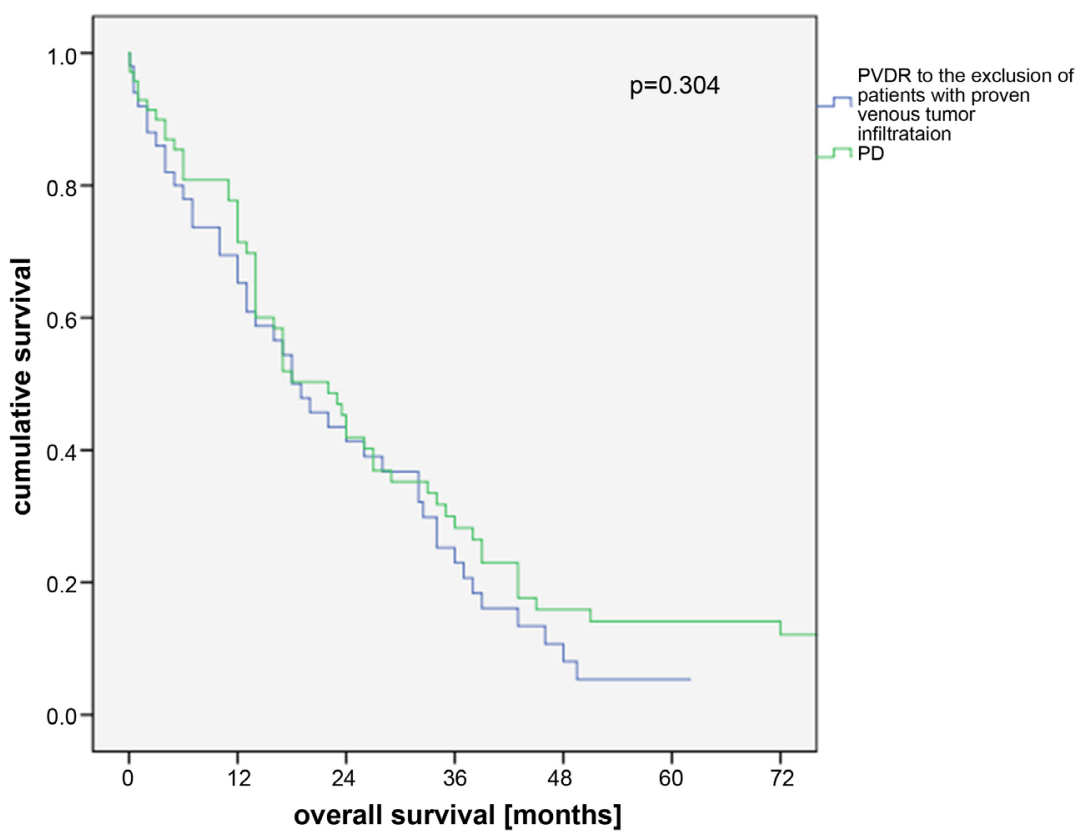

Figure 4. Overall survival after resection of pancreatic ductal adenocarcinoma stratified by the type of surgery, patients with proven venous tumor infiltration were excluded. PD = Pancreatoduodenectomy; PDVR = Pancreatoduodenectomy with simultaneous venous resection to the exclusion of patients with proven venous tumor infiltration (22 months, 95\% CI 16.02 - 27.99 vs. 19 months, 95\% CI 12.45 - 25.55).

Table 3. Univariate and multivariate analysis of factors associated with overall survival after resection of pancreatic ductal adenocarcinoma.

\begin{tabular}{|c|c|c|c|c|}
\hline \multirow[b]{2}{*}{ Variable } & \multicolumn{2}{|c|}{ Univariate analysis } & \multicolumn{2}{|c|}{ Multivariate analysis } \\
\hline & $\begin{array}{c}\text { Median overall } \\
\text { survival }(95 \% \mathrm{CI})\end{array}$ & $\mathrm{p}$-value & $\begin{array}{l}\text { Hazard ratio } \\
(95 \% \mathrm{CI})\end{array}$ & p-value \\
\hline \multicolumn{5}{|l|}{ Gender } \\
\hline Male & $22(14.11-29.89)$ & 0.351 & & \\
\hline Female & $14(10.37-17.62)$ & & & \\
\hline \multicolumn{5}{|l|}{ ASA-Score } \\
\hline 2 & $17(12.39-21.61)$ & 0.668 & & \\
\hline 3 & $18(10.55-25.45)$ & & & \\
\hline \multicolumn{5}{|c|}{ Type of surgery } \\
\hline $\mathrm{PD}$ & $22(16.02-27.99)$ & 0.087 & $0.877(0.518-1.483)$ & 0.624 \\
\hline PDVR & $16(9.96-22.04)$ & & & \\
\hline \multicolumn{5}{|c|}{$\begin{array}{l}\text { Histopathologically proven venous } \\
\text { tumor infiltration }\end{array}$} \\
\hline yes & $12(10.97-13.04)$ & 0.048 & $1.205(0.586-2.480)$ & 0.612 \\
\hline no & $19(13.67-24.33)$ & & & \\
\hline \multicolumn{5}{|l|}{ Tumor status } \\
\hline pT1 & $14(0-49.28)$ & 0.338 & & \\
\hline
\end{tabular}




\section{Continued}

pT2

pT3

pT4

Lymph node status

$\mathrm{pN} 0$

$\mathrm{pN} 1$

Resection status

R0

$\mathrm{R} 1$

Number of positive lymph nodes

$\begin{array}{cc}0 & 24(17.78-30.22) \\ 1-2(\text { median }) & 26(13.12-38.88) \\ >2 \text { (median) } & 14(7.97-20.03)\end{array}$

Lymph vascular invasion

L0

L1

Grading

G1

G2

G3

Operative time

$\leq 250$ min (median)

$>250 \mathrm{~min}$

Perioperative blood transfusion

$$
\text { yes }
$$

no

Intraoperative blood loss

$$
\leq 400 \mathrm{ml} \text { (median) }
$$

$>400 \mathrm{ml}$

Postoperative blood transfusion

$$
\text { yes }
$$$$
\text { no }
$$

Any postoperative complication

$$
\text { yes }
$$$$
\text { no }
$$

Major postoperative complication,

Clavien-Dindo $\geq 3$

$$
\begin{gathered}
34(23.20-44.80) \\
17(13.61-20.39) \\
18(9.20-26.80)
\end{gathered}
$$

$$
3(-)
$$

$14(8.40-19.60)$

$18(8.18-27.83)$

$17(12.00-22.00)$

$20(13.98-26.02)$

$18(12.24-23.76)$

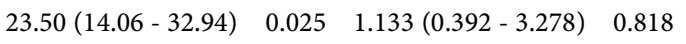

$$
\begin{array}{ll}
26(20.26-31.74) & 0.635 \\
17(12.40-21.60) &
\end{array}
$$$$
22(16.42-27.59) \quad 0.062 \quad 1.348(0.826-2.201) \quad 0.232
$$

$$
17(12.42-21.58) \quad 0.630
$$

$$
\begin{array}{ll}
14(3.20-24.68) & 0.544 \\
17(10.90-23.10) &
\end{array}
$$

$18(11.00 .25 .00) \quad 0.665$

$12(6.51-17.49) \quad 0.001 \quad 1.443(0.848-2.455) \quad 0.176$

$14(9.06-18.94) \quad 0.186 \quad 1.598(0.984-2.596) \quad 0.058$

yes

$12(11.36-12.64) \quad 0.233$ 


\section{Continued}

\begin{tabular}{ccc}
\hline no & $20(14.48-25.52)$ & \\
POPF & $18(13.19-22.81)$ & 0.706 \\
no, ISGPF Grade A & $13(2.36-23.65)$ & \\
ISGPF Grade B,C & \\
Reoperation & $12(2.50-21.50)$ & 0.974 \\
yes & $18(10.94-25.06)$ & \\
no & \\
DGE & $24(15.53-32.47)$ & 0.752 \\
yes & $17(13.45-20.55)$ & \\
no & & \\
Postoperative bleeding & $12(0-36.01)$ & 0.560 \\
yes & $17(11.03-22.97)$ & \\
no &
\end{tabular}

$\mathrm{PD}=$ Pancreatoduodenectomy; $\mathrm{PDVR}=$ Pancreatoduodenectomy with simultaneous venous resection; ASA-Score $=$ American Society of Anesthesiologists-Score; POPF = Postoperative pancreatic fistula; ISGPF

$=$ International Study Group of Pancreatic Fistula; DGE $=$ Delayed gastric emptying.

Multivariate analysis did not reveal any parameters with significant influence on overall survival (Table 3 ).

\section{Discussion}

Pancreatic ductal adenocarcinoma rates among the most common cancer related causes of death [3]). Neither today nor in the near future there will be any alternative curative therapy other than surgery. In fact, due to surgical as well as peri-, postoperative improvements and therefore decreasing peri- and postoperative morbidity and mortality [25], surgery plays an increasingly important part in the therapy of pancreatic ductal adenocarcinoma and the resection indications could be extended [26] [27] [28]. The core objective of these advanced, more radical surgeries, including among others extended lymphadenectomy [29], multivisceral resections [30] as well as synchronous arterial and venous resections, is to decrease the number of positive margins, a key prognostic factor [31] [32], even in those patients that present with a locally advanced tumor at the time of diagnosis (about one third of all patients [33]).

Nevertheless, in time of neoadjuvant therapeutic regimes the indication for primary resection of locally advanced pancreatic head cancer or at least tumors with either tumorous or inflammatory invasion of surrounding structures remain controversial. Therefore, the objective of the present study is to compare the long-term survival as well as the peri- and postoperative morbidity and mortality after primary resection without a neoadjuvant therapy of ductal pancreatic head cancer with involvement of the PV or/and the SMV with the standard procedure. 
The authors' analysis includes 71 patients that underwent PD with simultaneous venous resection at the time of ( $\mathrm{pp}-$ ) whipple procedure and another 71 patients with the same risk factors regarding age, gender and comorbidities that underwent standard PD.

As might be reasonably expected, most of the tumors were classified pT3 at final histopathological analysis and there was no statistically significant difference in their incidence between the two groups. In approximately one third of the specimen after PDVR, the tumor infiltration into the venous wall could histopathologically be confirmed. This finding underlines the difficulty to discriminate between real tumor infiltration or only peritumoral inflammatory involvement of the vessels, both on preoperative imaging and on the basis of the intraoperative macroscopic aspect [34] [35]. On final histopathological analysis the incidence of a positive lymph node status $(\mathrm{pN} 1)$ was higher in the PDVR group than in the PD group, even though it did not reach statistical significance. Further examination revealed that the number of harvested as well as the number of positive lymph nodes were significantly higher after PDVR compared to standard resection $(\mathrm{p}=0.025$ and $\mathrm{p}=0.001)$. The first aspect appears to be evident as the extended resection results in a larger number of harvested lymph nodes [34]. But the higher rate of positive lymph nodes in the PDVR group may be an indication that the venous tumor involvement is not only a consequence of the tumor location, close to the vein [12] [14] [15], but rather an indication of aggressive tumor biology resulting in early metastatic spread and infiltrating tumor growth [16] [17] [18] [19].

The authors' analysis shows a significantly lower rate of R0 resections in the PDVR group (53.52 vs. $71.83 \%, \mathrm{p}=0.024$ ). Further investigation of the PDVR subgroup reveals that especially histopathologically proven venous tumor infiltration is associated with a higher incidence of $\mathrm{R} 1$ resection status (47.62\%). This finding may be one of the reasons for the reduced overall survival of these patients [36], as written below, and can be supported by former studies: Malleo et al. [34] report a significantly higher incidence of $\mathrm{R} 1$ resection status of $60.7 \% \mathrm{vs}$. $35.6 \%$, if the tumor infiltration into the venous wall could be confirmed, maybe due to the close proximity of the tumor to the superior mesenteric artery neural plexus [13].

Regarding the peri- and postoperative outcome, the present analysis shows that the PD with simultaneous venous resection is not chancier than the standard procedure and can be performed safely at high volume centers [37] [38]: As described by several authors before [11] [34] [39] [40] [41] [42], the intrahospital mortality (5.63\% vs. $9.86 \%, \mathrm{p}=0.346$ ) did not differ significantly between the two groups. The overall incidence of complications was $56.34 \%$, comparable to the one reported by other high volume pancreatic surgeons [34]. Apart from the overall complication rate, the extent of the surgery does not significantly influence the incidence of major complications (Clavien-Dindo $\geq 3$ ) [38] [40] [43] or surgery associated complications such as relevant postoperative pancreatic fistu- 
la [34], bile fistula, postoperative bleeding, delayed gastric emptying and the rate of reoperations [34] [39]. As a consequence, the length of the stay on intensive care unit as well as the duration of the overall hospital stay also did not differ significantly between the two groups.

According to the present analysis, the median operation time and the median estimated intraoperative blood loss were comparable between the two groups. In contrast, Zhou et al. report that PDVR is associated with both a significantly higher estimated blood loss and operation time [39]. Despite the similar median estimated blood loss, peri- and postoperative blood transfusions were significantly more common in patients after PDVR, as reported by Wang et al. [13], too. One reason for this discrepancy may be that the venous resection might carry a higher risk for postoperative hemorrhage and therefore surgeons aim at a higher hemoglobin level in these patients in the early postoperative period.

The median overall survival of the 142 patients included in the study was 17 months (range 1 - 144 months), which is comparable to the results of Roch et al. [44]. Patients that underwent PD tend to have a longer median survival than those with simultaneous venous resection, but without statistical significance.

In contrast, the median overall survival of patients with histopathologically proven tumor infiltration into the venous wall was significantly worse than the survival rate of those without venous tumor infiltration [11] (12 months, 95\% CI 10.97 - 13.34 vs. 19 months, 95 CI 13.67 - 24.33; p = 0.048). As reported by Giovinazzo et al. [11] one reason for this finding may be the association between venous tumor infiltration and an increased rate of disease residual (R1), although the resection status ( $\mathrm{R} 0 \mathrm{vs}$. $\mathrm{R} 1$ ) does not reach statistical significance ( $\mathrm{p}=$ $0.066)$ in the present univariate analysis.

Instead the authors are able to show that the lymph node status, N0 vs. N1, has a significant influence on overall survival. This finding can be supported by further investigations according to which the venous tumor infiltration itself is proven to be an indication for a particular aggressive tumor biology that tends to early metastatic spread [16] [17] [18] [19]. Similarly, Delpero et al. [40] report that $\mathrm{R} 1$ resection status is frequently associated with nodal metastasis as well as increased lymph node ratio.

The present study also reveals the number of positive lymph nodes as prognostic factor for long-term survival that barely missed statistical significance ( $\mathrm{p}$ $=0.07$ ). Similar findings are reported by Banz et al. [45] who ascertained that patients with higher percentage of positive lymph nodes had a shorter survival independent of the vein resection status.

Another parameter that correlates significantly with overall survival on univariate analysis is the need for postoperative blood transfusions: On the one hand, they might be an indication for postoperative complications but, in the present analysis, the rate of postoperative complications in general as well as major complications, surgical associated or specific complications like reoperations, incidence of postoperative pancreatic fistula, bile fistula, postoperative bleeding have no significant influence on overall survival. On the other hand, the negative 
impact of blood transfusions themselves on overall survival has been demonstrated well in the past [46] [47], although the underlying mechanisms remain mostly speculative [37].

There are some limitations of the study. It is a single center study and a retrospective analysis. Although it is one of the largest single center studies that have been reported, it is nevertheless a quite small group of patients and therefore the statistical power is limited. Another point is that the study does not provide information about the extent of venous resection, wedge resection or segmental resection, nor the prevalence of a postoperative chemotherapy.

\section{Conclusion}

With these limitations in mind, the present study demonstrates that PDVR is not associated with increased peri- and post-operative morbidity and mortality compared to standard PD and can be performed safely at high volume centers. Furthermore, the authors support the oncologic tumor resection in case of preoperative or intraoperative signs of venous tumor involvement. First, as a remarkable percentage of tumors do not infiltrate the venous wall according to the final histopathological analysis, as could be shown by the authors, it is not justified to withhold these patients the chance of cure. Second, even in case of confirmed venous tumor infiltration on postoperatively histopathological analysis, patients benefit from a better overall survival compared to patients that receive only a palliative chemotherapy [48] or undergo palliative bypass surgery [49].

\section{Conflicts of Interest}

None.

\section{References}

[1] AWMF. (2013) S3-Leitlinie Zum Exokrinen Pankreaskarzinom, Version 1.0. http://www.awmf.org/uploads/tx_szleitlinien/032-010OLl_S3_Exokrines_Pankreask arzinom_21112013pdf

[2] Yeo, C.J., Cameron, J.L., Lillemoe, K.D., Sohn, T.A., Campbell, K.A., Sauter, P.K., et al. (2002) Pancreaticoduodenectomy with or without Distal Gastrectomy and Extended Retroperitoneal Lymphadenectomy for Periampullary Adenocarcinoma, Part 2: Randomized Controlled Trial Evaluating Survival, Morbidity, and Mortality. Annals of Surgery, 236, 355-366.

[3] Jemal, A., Tiwari, R.C., Murray, T., Ghafoor, A., Samuels, A., Ward, E., et al. (2004) Cancer Statistics, 2004. CA: A Cancer Journal for Clinicians, 54, 8-29. https://doi.org/10.3322/canjclin.54.1.8

[4] Poruk, K.E. and Weiss, M.J. (2015) The Current State of Surgery for Pancreatic Cancer. Minerva Gastroenterologica e Dietologica, 61, 101-115.

[5] Shaib, Y., Davila, J., Naumann, C. and El-Serag, H. (2007) The Impact of Curative Intent Surgery on the Survival of Pancreatic Cancer Patients: A U.S. Population-Based Study. American Journal of Gastroenterology, 102, 1377-1382. https://doi.org/10.1111/j.1572-0241.2007.01202.x 
[6] Hartwig, W., Hackert, T., Hinz, U., Gluth, A., Bergmann, F., Strobel, O., et al. (2011) Pancreatic Cancer Surgery in the New Millennium: Better Prediction of Outcome. Annals of Surgery, 254, 311-319. https://doi.org/10.1097/SLA.0b013e31821fd334

[7] Mayo, S.C., Nathan, H., Cameron, J.L., Olino, K., Edil, B.H., Herman, J.M., et al. (2012) Conditional Survival in Patients with Pancreatic Ductal Adenocarcinoma Resected with Curative Intent. Cancer, 118, 2674-2681. https://doi.org/10.1002/cncr.26553

[8] Glanemann, M., Shi, B., Liang, F., Sun, X.G., Bahra, M., Jacob, D., et al. (2008) Surgical Strategies for Treatment of Malignant Pancreatic Tumors: Extended, Standard or Local Surgery? World Journal of Surgical Oncology, 6, 123. https://doi.org/10.1186/1477-7819-6-123

[9] Harrison, L.E., Klimstra, D.S. and Brennan, M.F. (1996) Isolated Portal Vein Involvement in Pancreatic Adenocarcinoma. A Contraindication for Resection? Annals of Surgery, 224, 342-347. https://doi.org/10.1097/00000658-199609000-00010

[10] Ghaneh, P., Costello, E. and Neoptolemos, J.P. (2007) Biology and Management of Pancreatic Cancer. Gut, 56, 1134-1152. https://doi.org/10.1136/gut.2006.113068

[11] Giovinazzo, F., Turri, G., Katz, M.H., Heaton, N. and Ahmed, I. (2016) Meta-Analysis of Benefits of Portal-Superior Mesenteric Vein Resection in Pancreatic Resection for Ductal Adenocarcinoma. British Journal of Surgery, 103, 179-191. https://doi.org/10.1002/bjs.9969

[12] Yekebas, E.F., Bogoevski, D., Cataldegirmen, G., Kunze, C., Marx, A., Vashist, Y.K., et al. (2008) En Bloc Vascular Resection for Locally Advanced Pancreatic Malignancies Infiltrating Major Blood Vessels: Perioperative Outcome and Long-Term Survival in 136 Patients. Annals of Surgery, 247, 300-309. https://doi.org/10.1097/SLA.0b013e31815aab22

[13] Wang, F., Arianayagam, R., Gill, A., Puttaswamy, V., Neale, M., Gananadha, S., et al. (2012) Grafts for Mesenterico-Portal Vein Resections Can Be Avoided during Pancreatoduodenectomy. Journal of the American College of Surgeons, 215, 569-579. https://doi.org/10.1016/j.jamcollsurg.2012.05.034

[14] Tseng, J.F., Raut, C.P., Lee, J.E., Pisters, P.W., Vauthey, J.N., Abdalla, E.K., et al. (2004) Pancreaticoduodenectomy with Vascular Resection: Margin Status and Survival Duration. Journal of Gastrointestinal Surgery, 8, 935-950.

https://doi.org/10.1016/j.gassur.2004.09.046

[15] Kelly, K.J., Winslow, E., Kooby, D., Lad, N.L., Parikh, A.A., Scoggins, C.R., et al. (2013) Vein Involvement during Pancreaticoduodenectomy: Is There a Need for Redefinition of "Borderline Resectable Disease"? Journal of Gastrointestinal Surgery, 17, 1209-1217. https://doi.org/10.1007/s11605-013-2178-5

[16] Capussotti, L., Massucco, P., Ribero, D., Vigano, L., Muratore, A. and Calgaro, M. (2003) Extended Lymphadenectomy and Vein Resection for Pancreatic Head Cancer: Outcomes and Implications for Therapy. Archives of Surgery, 138, 1316-1322. https://doi.org/10.1001/archsurg.138.12.1316

[17] Shimada, K., Sano, T., Sakamoto, Y. and Kosuge, T. (2006) Clinical Implications of Combined Portal Vein Resection as a Palliative Procedure in Patients Undergoing Pancreaticoduodenectomy for Pancreatic Head Carcinoma. Annals of Surgical Oncology, 13, 1569-1578. https://doi.org/10.1245/s10434-006-9143-4

[18] Christians, K. and Evans, D.B. (2009) Pancreaticoduodenectomy and Vascular Resection: Persistent Controversy and Current Recommendations. Annals of Surgical Oncology, 16, 789-791. https://doi.org/10.1245/s10434-009-0322-y 
[19] Yamada, S., Fujii, T., Sugimoto, H., Nomoto, S., Takeda, S., Kodera, Y., et al. (2013) Aggressive Surgery for Borderline Resectable Pancreatic Cancer: Evaluation of $\mathrm{Na}$ tional Comprehensive Cancer Network Guidelines. Pancreas, 42, 1004-1010. https://doi.org/10.1097/MPA.0b013e31827b2d7c

[20] Barbier, L., Turrini, O., Gregoire, E., Viret, F., Le Treut, Y.P. and Delpero, J.R. (2011) Pancreatic Head Resectable Adenocarcinoma: Preoperative Chemoradiation Improves Local Control But Does Not Affect Survival. $H P B, 13,64-69$. https://doi.org/10.1111/j.1477-2574.2010.00245.x

[21] Chun, Y.S., Milestone, B.N., Watson, J.C., Cohen, S.J., Burtness, B., Engstrom, P.F., et al. (2010) Defining Venous Involvement in Borderline Resectable Pancreatic Cancer. Annals of Surgical Oncology, 17, 2832-2838. https://doi.org/10.1245/s10434-010-1284-9

[22] Siriwardana, H.P. and Siriwardena, A.K. (2006) Systematic Review of Outcome of Synchronous Portal-Superior Mesenteric Vein Resection during Pancreatectomy for Cancer. British Journal of Surgery, 93, 662-673. https://doi.org/10.1002/bjs.5368

[23] Bassi, C., Dervenis, C., Butturini, G., Fingerhut, A., Yeo, C., Izbicki, J., et al. (2005) Postoperative Pancreatic Fistula: An International Study Group (ISGPF) Definition. Surgery, 138, 8-13. https://doi.org/10.1016/j.surg.2005.05.001

[24] Amin, M.B., Edge, S., Greene, F., Byrd, D.R., Brookland, R.K., Washington, M.K., et al. (2010) AJCC Cancer Staging Manual. 7th Edition, Springer, Berlin.

[25] Hartwig, W., Vollmer, C.M., Fingerhut, A., Yeo, C.J., Neoptolemos, J.P., Adham, M., et al. (2014) Extended Pancreatectomy in Pancreatic Ductal Adenocarcinoma: Definition and Consensus of the International Study Group for Pancreatic Surgery (ISGPS). Surgery, 156, 1-14. https://doi.org/10.1016/j.surg.2014.02.009

[26] Salem, A.I., Alfi, M., Winslow, E., Cho, C.S. and Weber, S.M. (2015) Has Survival Following Pancreaticoduodenectomy for Pancreas Adenocarcinoma Improved over Time? Journal of Surgical Oncology, 112, 643-649. https://doi.org/10.1002/jso.24048

[27] Winter, J.M., Cameron, J.L., Campbell, K.A., Arnold, M.A., Chang, D.C., Coleman, J., et al. (2006) 1423 Pancreaticoduodenectomies for Pancreatic Cancer: A Single-Institution Experience. Journal of Gastrointestinal Surgery, 10, 1199-1210. https://doi.org/10.1016/j.gassur.2006.08.018

[28] Yeo, C.J., Cameron, J.L., Sohn, T.A., Lillemoe, K.D., Pitt, H.A., Talamini, M.A., et al. (1997) Six Hundred Fifty Consecutive Pancreaticoduodenectomies in the 1990s: Pathology, Complications, and Outcomes. Annals of Surgery, 226, 248-257. https://doi.org/10.1097/00000658-199709000-00004

[29] Naganuma, T., Isaji, S. and Kawarada, Y. (1998) Staging and Extended Resection for Pancreatic Cancer. Pancreas, 16, 355-362. https://doi.org/10.1097/00006676-199804000-00024

[30] Sasson, A.R., Hoffman, J.P., Ross, E.A., Kagan, S.A., Pingpank, J.F. and Eisenberg, B.L. (2002) En Bloc Resection for Locally Advanced Cancer of the Pancreas: Is It Worthwhile? Journal of Gastrointestinal Surgery, 6, 147-157. https://doi.org/10.1016/S1091-255X(01)00063-4

[31] Yamamoto, T., Yagi, S., Kinoshita, H., Sakamoto, Y., Okada, K., Uryuhara, K., et al. (2015) Long-Term Survival after Resection of Pancreatic Cancer: A Single-Center Retrospective Analysis. World Journal of Gastroenterology, 21, 262-268. https://doi.org/10.3748/wjg.v21.i1.262

[32] Howard, T.J., Krug, J.E., Yu, J., Zyromski, N.J., Schmidt, C.M., Jacobson, L.E., et al. (2006) A Margin-Negative R0 Resection Accomplished with Minimal Postoperative 
Complications Is the Surgeon's Contribution to Long-Term Survival in Pancreatic Cancer. Journal of Gastrointestinal Surgery, 10, 1338-1345. https://doi.org/10.1016/j.gassur.2006.09.008

[33] Malik, N.K., May, K.S., Chandrasekhar, R., Wee, W., Flaherty, L., Iyer, R., et al. (2012) Treatment of Locally Advanced Unresectable Pancreatic Cancer: A 10-Year Experience. Journal of Gastrointestinal Oncology, 3, 326-334.

[34] Malleo, G., Maggino, L., Marchegiani, G., Feriani, G., Esposito, A., Landoni, L., et al. (2017) Pancreatectomy with Venous Resection for pT3 Head Adenocarcinoma: Perioperative Outcomes, Recurrence Pattern and Prognostic Implications of Histologically Confirmed Vascular Infiltration. Pancreatology, 17, 847-857. https://doi.org/10.1016/j.pan.2017.08.005

[35] Ramacciato, G., Mercantini, P., Petrucciani, N., Giaccaglia, V., Nigri, G., Ravaioli, M., et al. (2009) Does Portal-Superior Mesenteric Vein Invasion Still Indicate Irresectability for Pancreatic Carcinoma? Annals of Surgical Oncology, 16, 817-825. https://doi.org/10.1245/s10434-008-0281-8

[36] Wagner, M., Redaelli, C., Lietz, M., Seiler, C.A., Friess, H. and Buchler, M.W. (2004) Curative Resection Is the Single Most Important Factor Determining Outcome in Patients with Pancreatic Adenocarcinoma. British Journal of Surgery, 91, 586-594. https://doi.org/10.1002/bjs.4484

[37] Kulemann, B., Hoeppner, J., Wittel, U., Glatz, T., Keck, T., Wellner, U.F., et al. (2015) Perioperative and Long-Term Outcome after Standard Pancreaticoduodenectomy, Additional Portal Vein and Multivisceral Resection for Pancreatic Head Cancer. Journal of Gastrointestinal Surgery, 19, 438-444. https://doi.org/10.1007/s11605-014-2725-8

[38] Yu, X.Z., Li, J., Fu, D.L., Di, Y., Yang, F., Hao, S.J., et al. (2014) Benefit from Synchronous Portal-Superior Mesenteric Vein Resection during Pancreaticoduodenectomy for Cancer: A Meta-Analysis. European Journal of Surgical Oncology, 40, 371-378. https://doi.org/10.1016/j.ejso.2014.01.010

[39] Zhou, Y., Zhang, Z., Liu, Y., Li, B. and Xu, D. (2012) Pancreatectomy Combined with Superior Mesenteric Vein-Portal Vein Resection for Pancreatic Cancer: A Meta-Analysis. World Journal of Surgery, 36, 884-891. https://doi.org/10.1007/s00268-012-1461-z

[40] Delpero, J.R., Boher, J.M., Sauvanet, A., Le Treut, Y.P., Sa-Cunha, A., Mabrut, J.Y., et al. (2015) Pancreatic Adenocarcinoma with Venous Involvement: Is Up-Front Synchronous Portal-Superior Mesenteric Vein Resection Still Justified? A Survey of the Association Francaise de Chirurgie. Annals of Surgical Oncology, 22, 1874-1883. https://doi.org/10.1245/s10434-014-4304-3

[41] Barreto, S.G. and Windsor, J.A. (2016) Justifying Vein Resection with Pancreatoduodenectomy. The Lancet Oncology, 17, e118-e124. https://doi.org/10.1016/S1470-2045(15)00463-5

[42] Ravikumar, R., Sabin, C., Abu Hilal, M., Bramhall, S., White, S., Wigmore, S., et al. (2014) Portal Vein Resection in Borderline Resectable Pancreatic Cancer: A United Kingdom Multicenter Study. Journal of the American College of Surgeons, 218, 401-411. https://doi.org/10.1016/j.jamcollsurg.2013.11.017

[43] Wang, W.L., Ye, S., Yan, S., Shen, Y., Zhang, M., Wu, J., et al. (2015) Pancreaticoduodenectomy with Portal Vein/Superior Mesenteric Vein Resection for Patients with Pancreatic Cancer with Venous Invasion. Hepatobiliary \& Pancreatic Diseases International, 14, 429-435. https://doi.org/10.1016/S1499-3872(15)60400-3

[44] Roch, A.M., House, M.G., Cioffi, J., Ceppa, E.P., Zyromski, N.J., Nakeeb, A., et al. 
(2016) Significance of Portal Vein Invasion and Extent of Invasion in Patients Undergoing Pancreatoduodenectomy for Pancreatic Adenocarcinoma. Journal of Gastrointestinal Surgery, 20, 479-487. https://doi.org/10.1007/s11605-015-3005-y

[45] Banz, V.M., Croagh, D., Coldham, C., Taniere, P., Buckels, J., Isaac, J., et al. (2012) Factors Influencing Outcome in Patients Undergoing Portal Vein Resection for Adenocarcinoma of the Pancreas. European Journal of Surgical Oncology, 38, 72-79. https://doi.org/10.1016/j.ejso.2011.08.134

[46] Cameron, J.L., Crist, D.W., Sitzmann, J.V., Hruban, R.H., Boitnott, J.K., Seidler, A.J., et al. (1991) Factors Influencing Survival after Pancreaticoduodenectomy for Pancreatic Cancer. The American Journal of Surgery, 161, 120-124. https://doi.org/10.1016/0002-9610(91)90371-J

[47] Yeh, J.J., Gonen, M., Tomlinson, J.S., Idrees, K., Brennan, M.F. and Fong, Y. (2007) Effect of Blood Transfusion on Outcome after Pancreaticoduodenectomy for Exocrine Tumour of the Pancreas. British Journal of Surgery, 94, 466-472. https://doi.org/10.1002/bjs.5488

[48] Doi, R., Imamura, M., Hosotani, R., Imaizumi, T., Hatori, T., Takasaki, K., et al. (2008) Surgery versus Radiochemotherapy for Resectable Locally Invasive Pancreatic Cancer: Final Results of a Randomized Multi-Institutional Trial. Surgery Today, 38, 1021-1028. https://doi.org/10.1007/s00595-007-3745-8

[49] Lygidakis, N.J., Singh, G., Bardaxoglou, E., Dedemadi, G., Sgourakis, G., Nestoridis, J., et al. (2004) Mono-Bloc Total Spleno-Pancreaticoduodenectomy for Pancreatic Head Carcinoma with Portal-Mesenteric Venous Invasion. A Prospective Randomized Study. Hepato-Gastroenterology, 51, 427-433. 